\title{
On Possible Problems of Labor Market in Digital Era
}

\author{
Romanov D.V.* \\ Samara State Agrarian University \\ Kinel, Samara Region, Russia \\ e-mail: dmitrom@rambler.ru
}

\author{
Filatov T.V. \\ Samara State Agrarian University \\ Kinel, Samara Region, Russia
}

\begin{abstract}
The article discusses the impact of economy digitalization on the labor market. The applicability of an interdisciplinary approach for resolving the stated problem, which is considered in the work from the philosophical and pedagogical perspectives, is substantiated. An analysis of the trends in the development of information and computer technologies (ICT) and artificial intelligence (AI) technologies has shown that the works of economists underestimate the possible negative impact of these technologies expansion on the labor market. Most of the existing professions including the ones from the field of education are at risk in terms of a dramatic reduction in the human resources involved or full automation of the corresponding activities. It is shown that this process can result only in the transformation of alienated labor into free labor, which will lead to a qualitative change in production relations. Accordingly, the educational philosophy, which in the near historical perspective will completely lose its pragmatic component, should change qualitatively.
\end{abstract}

Keywords - labor market, digital era, human resources, economy digitalization

\section{INTRODUCTION}

Economy digitalization is an irreversible process that is being carried out literally before our eyes. It concerns not only the spread of information and computer technologies (ICT) but rather the introduction of artificial intelligence (AI) systems into the economy and management as well as the processes of robotics, the replacement of workers with robots and more complex automated systems, which potentially threatens humanity with global unemployment. In addition to the psychological problems associated with the global restructuring of industrial production, the economy digitalization in the near future may lead to qualitative changes in the traditional forms of social life of mankind. The possible consequences of such changes cannot be currently calculated with a sufficient degree of accuracy. In accordance with the well-known position of Marxist philosophy on economics being the real basis of society, over which a political, ideological and other superstructure rises [1, p. 6-7], economy digitalization is likely to lead to revolutionary changes in trade, education, socio-political sphere, etc.

In this work, we focus only on one of the possible consequences of digitalization being a qualitative change in the labor market in Russia and in the world, which it may result in. Many professions, whose representatives feel quite confident and comfortable today, fall into the risk zone. Moreover, many professions students in Russian and foreign universities are trained for today may no longer exist in the coming decades when graduates only begin their career.

It is known that the social and humanitarian sphere involves the study of complex systems with selfconsciousness. These systems are characterized by multivariate development and multifactorial nature, the essence of which consists in the fact that social humanitarian systems are affected by many factors, unlike simple mechanical systems with unambiguous determination. It is this circumstance that makes such systems almost unpredictable, since we do not know which of the many factors will be crucial (dominant) in a particular situation. On the other hand, multifactor applied to these objects makes interdisciplinary research effective when the representatives of various disciplines consider joining in order to examine the studied object from different angles, highlighting those factors which the representative neighboring discipline simply does not pay attention to. Meanwhile, economy digitalization as well as the state of the labor market is considered mainly in the studies of economists.

In order to fill this gap, the authors of this article will try to consider the philosophical and pedagogical aspects of the digitalization phenomenon.

\section{LITERATURE REVIEW}

In the $40 \mathrm{~s}$ of the twentieth century two significant scientific works were written almost simultaneously. They are as follows: the book by N. Wiener "Cybernetics" [2], whose framework led to the first step in the direction of modern information and computer technologies (ICT), which, eventually resulted in artificial intelligence technologies and the upcoming economy digitalization. The second work, worth drawing attention to, is the book of K.R. Popper "Open Society and Its Enemies" [3, 4]. As Popper was one of the largest representatives of the philosophy of science, he devoted his work to the criticism of one of the basic branches of socio-philosophical thinking, dating back to the theory of the ideal state of Plato. According to Popper, it was the Platonic oracle philosophy that led to the emergence of the socalled totalitarian societies, whose distinguishing feature was the dictatorship of the masses, which quantitatively suppresses the intellectually and culturally advanced minorities, which previously invariably dominated in traditional societies. Even before Popper, this process was described by J. Ortega y Gasset in his work "Rise of the Masses" [5]. 
Factually, the twentieth century was characterized by crowds, mass events, which in the era of globalization acquire a planetary character, such as the Olympic Games or the World Cups. As for the era directly criticized by Popper, here attention is drawn, first of all, to mass production, huge heaps of people participating in world wars, mass political demonstrations, hypermarkets, visited by mass buyers, mass parades, etc. Being an intellectual and a liberal, Popper not only criticizes the totalitarian projects of an ideal social structure, which he relates communism and fascism to, but also contrasted them with his ideal, which he called "abstract society" [4].

The signs that Popper endowed this society with are noteworthy. Firstly, people of this society live exclusively in cottages, in order to minimize any contacts with neighbors. Secondly, in modern terms, most people (ideally everyone) work remotely. For example, a teacher remotely works with students; a scientist sends his articles by mail to journals, etc. Thirdly, everything necessary for life, from food to newspapers, is delivered to a person remotely, to the threshold of his house, after paying a preliminary order. Fourthly, in case of emergency, people move around the city in a car with tinted windows, and no one has the right to stop them and to pull them out of the car without extreme need.

It is easy to notice that the abstract society described by Popper coincides with the society whose basis is the digital economy with regards to its main parameters. For example, G.G. Golovenchik [6] points out the following advantages of digital employment: reducing time and costs of transportation, ability to work in a familiar home environment, optimized balance between work, leisure and socializing with the family, new prospects for participating in social life (remotely), ability to preserve skills and improve qualifications (for example, through distance education), a flexible work schedule, a wide network of useful contacts and contacts.

Additionally, adoption of a self-isolation mode at the beginning of 2020 due to the coronavirus epidemy by a number of states, including Russia can be considered as a useful social experience that allowed hundreds of millions of people to psychologically experience the realities of the future society of an advanced digital economy.

However, the greatest fears associated with the transition to a digital economy are caused by a psychological restructuring that is associated not with this transition with the aim to adapt to qualitatively new conditions of labor activity but with the possible catastrophic withdrawal of the labor market. A similar fear is expressed, for example, in the work of Andreeva L.Yu. and Dzhemaeva O.T. [7], which states that the Russian labor market shows a clear tendency to shrink, that is, more jobs are steadily being eliminated than the new ones are being created. So far, this trend is relatively weak but its development, which is expected to intensify during the total transition to digital technologies, graphically gives the Russian labor market the form of a twisting spiral.

Furthermore, the researchers noted another selfcontradictory tendency that manifests itself in the course of the domestic labor market transformation and is pointed at by O.D. Kuksova [8]. On the one hand, in Russia there is a clear overabundance of a number of professions which are at risk in connection with the transition to a digital economy. First of all, these are lawyers and economists who, in modern conditions, experience the greatest difficulties with finding a job. On the other hand, there is a clear shortage of ICT specialists in the Russian labor market, although this area itself forms a very modest segment of the Russian economy. Thus, in 2015, only $2 \%$ of the total employed population of the Russian Federation was involved in this area, which is three times lower than the corresponding indicators in Finland $(6.05 \%)$ and 2 times lower than in the USA (4.07\%). Hence, the researcher concludes that the economy of the Russian Federation as a whole and the labor market in particular are not fully prepared to switch to the digital economy [8, p. 61].

The article by E.A. Nekrasova [9] points to a key negative trend associated with the prospect of a global transition of mankind to a digital economy. According to the researcher, relying on the study of foreign experts in the corresponding field, about $50 \%$ of modern mass professions will disappear in 15-20 years. The latter, in turn, will inevitably lead to the escalation of two social problems: intensification of social inequality and a dramatic increase in the number of unemployed. E.S. Sadovaya [10] indicates that the risk groups are primarily in the area in which automation and robotics technologies may turn out to be very effective. For example, according to the PWC report, $38 \%$ of jobs can be automated in the USA, $35 \%$, in Germany, $30 \%$ in the UK and $21 \%$ in Japan by 2030. A World Bank report on Digital Dividends states that in developing countries, where the percentage of people employed in unskilled physical labor is particularly high and equals approximately two thirds of all, jobs can be automated. The topic of automation is supplemented by the topic of robotization in the above-mentioned work of G.G. Golovenchika [6], who, based on the opinions of reputable expert communities such as the Superjob recruiting portal, the American market research company Forrester Research, the Brookfield Institute for Innovation and Entrepreneurship, the Nomura Research Institute, indicates that by 2024 robots will replace every fourth employer of Russia, by $2025,7 \%$ of the employers in the USA, by 2026 , $40 \%$ of the employers Canada and, finally, by 2035, $50 \%$ of the employers Japan. In 2017, South Korea was the most robotized country in the world, where 630 industrial robots accounted for 10 thousand workers. And $52 \%$ of industrial robots in 2017 were made by Japan.

\section{RESEARCH METHODOLOGY}

The methodological basis of this study is an interdisciplinary approach. Elements of a systematic approach and synergetics are also involved. Since the study is focused on clarifying the philosophical and pedagogical aspects of the possible impact of digitalization of the economy on the labor market, we use the philosophical method of rising from the abstract to the concrete.

Since the economy digitalization is an objective process, economists are psychologically inclined towards its positive interpretation. In particular, G.G. Golovenchik [6], relying on the report of the World Economic Forum "The Future of the Jobs 2018", argues that by 2022, 75 million jobs will be 
eliminated through the robotization of the corresponding types of professional activity. However, this is offset by the creation of 133 million new jobs, requiring their applicants to be proficient in ICT. As a result, the researcher makes the final conclusion that, despite the significant transformation of the labor market, the prospects in this area as a whole remain positive since jobs with pronounced human skills will continue to be in demand. Robots will not be able to displace scientists, engineers, actors, leaders, teachers, social workers [6, p. 37].

Such an assessment, in our opinion, is largely due to the narrow specialization of the researcher, who, as an economist, clearly underestimates the capabilities of modern artificial intelligence (AI) technologies. In this connection, it's enough to recall at least virtual reality technologies in modern art [11], which allow, for example, creating virtual musical groups consisting of participants drawn on a computer performing works synthesized by music computer programs. However, we will focus not on art and management but on the professional sphere of education closer to the authors of the article. Here, not everything is as simple as it might seem from the perspective of economic appropriateness.

In this regard, we would like to refer to an article by Borzova E.V. "On the uncertain future profession of a teacher of a foreign language" [12]. The author of the study has a paradoxical idea that foreign language teachers are also at risk due to the development of artificial intelligence technologies and transition to a digital economy. One would think, what representatives of this profession have in common with loaders, builders and drivers who are obviously at risk? Moreover, the Government of the Russian Federation in every possible way contributes to the expansion of the foreign languages training in schools and universities to the extent of introducing Unified State Examination in this subject compulsory for all graduates.

However, the reverse of the coin is obvious as well. Electronic online translators are constantly improving, so even today the level of mechanical translation, when using a program of a sufficient degree of complexity, is not inferior to the translation made by a professional philologist. Moreover, the development of appropriate artificial intelligence technologies in the near future with almost one hundred percent probability will lead to the fact that the pragmatic meaning of learning a foreign language being the ability of effective communication with native speakers will turn out to be completely devalued.

In the new reality, the immediate communication of this kind requires only a last-generation cell phone with an Internet connection and appropriate software. Thus, the study of living foreign languages will turn into the same exotic element of the educational system, which is now the study of ancient Greek and Latin, relevant only for a very narrow circle of classical philologists.

It is clear that teachers of other academic disciplines are in the same situation as teachers of foreign languages. For example, distance education technologies in the form of video lectures can reduce the number of employees involved in the educational process by reducing the amount of lecture load. Similarly, the use of test technologies can significantly reduce the volume of seminars of the classical type, especially in humanities disciplines. On the whole, the development of artificial intelligence technologies in the near future should lead to the complete replacement of human teachers with androids connected to the necessary sources of information, including the largest scientific libraries.

This marks the problem affecting the sphere of education in two ways. As far back as 2015, Australian researchers found that $60 \%$ of university students are trained in specialties, most specialists of which will be swept out by robots and artificial intelligence systems during the next 10-15 years. On the other hand, according to the estimates of analysts at the World Economic Forum, $65 \%$ of students who went to first grade in 2018 will ultimately be forced to master professions that did not exist at the time they started their education [6]. The latter focuses educational institutions on the introduction of innovative teaching methods. The educational system should be flexible enough. Otherwise, the courses of study offered by specific higher education institutions that are in demand today may well turn out to be unclaimed by the time students receive a diploma of higher education.

\section{CONCLUSION}

The interdisciplinary analysis carried out in the present work and concerning the problem of the impact of digitalization of the world economy in general and of the Russian economy in particular with the use of conceptual philosophizing technologies [13] enables to consider this problem from a new angle, which, in turn, results in the following conclusions.

1. Economy digitalization will necessarily strengthen human society atomization. In 2017 , in the USA, $36 \%$ of the ablebodied population (57.3 million people) worked in freelance mode, including remote and part-time ones [6, p. 28], and subsequently the number of freelancers in the world will only increase. Thus, we can state the end of the popular revolt era distinguished by mass production, mass culture, mass events (mass sports, parades and other mass festivals, political demonstrations, hypermarkets, etc.). The future of mankind is not a victorious procession of the millions of proletarians (communists, fascists, believers, sports fans, etc.), but the abstract society of Karl Popper, where any physical contacts between people are minimized to the maximum degrees.

2. The analysis showed that the negative impact of the economy digitalization on the state of the world labor market in economically oriented works is deliberately underestimated. This is due to the economists' fundamental underestimation of the potential capabilities of artificial intelligence (AI) technologies, whose development over one or two decades is most likely to lead to a catastrophic closing-up of the world labor market and to the entry of mankind into the era of mass unemployment. This leads to an active growth in the contemporary intellectual community of anti-scientist sentiments, which find their expression in the works of V.A. Kutyreva [14], who considers technologies of artificial interest as the main threat to the existence of mankind.

However, such a reaction to another destruction of the traditional world order through the technological revolution in 
the economy does not seem to be adequate. At the beginning of this article, we referred to the interpretation of economics by K. Marx and F. Engels as the real basis of society [1]. Now it is time to recall the second key idea of Marxism about the transition of mankind from the last class capitalist formation to a classless communist society. The idea of communism is simple: the permanent growth of labor productivity, which reaches its peak under capitalism, will sooner or later make the exploitation of man completely senseless. And this will happen when the economic activity will be for the most part or even completely carried out without the involvement of human labor. Thus, the level of productive forces development will lead to a qualitative change in production relations in society, more precisely, to their complete cessation. Human labor will cease to be a vital necessity for people and will become free.

3. Economy digitalization also poses serious problems in the field of education, which are not fully understood by professional educators. Since in our time the majority of modern professions are at risk due to the possibility of automation and robotization of the corresponding types of professional activities, including the education sector itself, this sphere loses its traditional historical stability, which updates the innovative approach to educational activities. In other words, the education system can exist only in the mode of permanent transformation, since the professions that students are currently getting can begin to reduce or even disappear by the time they graduate from the corresponding educational institutions.

In our opinion, the educational survival strategy described above is not satisfactory. It is necessary to take into account the tendency to devalue the pragmatic meaning of education in the conditions of the transformation of labor activity from a not free form to a free one. Even today, many people in the West receive higher education on retirement, which, obviously, is economically senseless. Therefore, the promising areas of modern pedagogy are, first of all, androgogy and gerontopedagogy [15]. In this connection, in the modern world, various forms of handicraft, opposed to mass production and also economically senseless in its traditional understanding, are spreading.

Thus, certain prospects for the survival of the education system in the modern world can be achieved only by a radical change in the philosophy of education in terms of rejecting the pragmatic interpretation of the meaning of education and training, which will still be lost in the immediate historical perspective. Thus, a dialectical return to the classical meaning of education, which took shape in the era of antiquity, when education was considered, first of all, as the main means of self-development of a person, should occur.

\section{References}

[1] K. Marx, F. Engels, "To a Critique of Political Economy", Soch., vol. 13, pp. 1-183.

[2] N. Wiener, Cybernetics, or control and communication in the animal and machine, Per. from Engl. Moscow: Nauka, 1983, 344 p.

[3] K.R. Popper, Open society and its enemies, In 2 volumes, vol. 1, The Enchantment of Plato. Moscow: Phoenix, 1992, 448 p.

[4] K.R. Popper, Open society and its enemies, In 2 volumes, vol. 2, The time of the false prophets: Hegel, Marx and other oracles. Moscow: Phoenix, 1992, 528 p.

[5] J. Ortega y Gasset, Rise of the masses. Moscow: AST, 2008, 352 p.

[6] G.G. Golovenchik, "Labor Market Transformation in the Digital Economy" Digital Transform., no. 4, pp. 27-43, 2018. eLIBRARY ID 37000892

[7] L.Yu. Andreeva, O.T. Dzhemayev, "The influence of the digita economy on the formation of new trends in the Russian labor market", State and Municipal Administration. Scholarly notes of SKAGS, no. 3 , pp. 25-32, 2017. eLIBRARY ID: 30094732

[8] O.D. Kuksova, "Problems of development of the Russian labor market during the transition to the digital economy", Society: politics, econ., law, no. 8, pp. 57-61, 2017. eLIBRARY ID: 29870481

[9] E.A. Nekrasova, "The labor market in the digital economy", Central Sci Herald, vol. 3, no. 22S(63S), pp. 35-36, 2018. eLIBRARY ID: 36524470

[10] E.S. Sadovaya, "Digital economy and the new paradigm of the labor market”, World Econ. and Int. Relat., vol. 62, no. 12, pp. 35-45, 2018. eLIBRARY ID: 36717257

[11] U.D. Kondratyeva, "The islands of the future diarrhea around us: virtua and augmented reality in art", Media, Inform., Communicat., no 29, pp. 20-26, 2019. eLIBRARY ID: 41436771

[12] E.V. Borzova, "About the uncertain future profession of a teacher of a foreign language", Domestic and foreign pedag., vol. 1, no. 6(56), pp. 124-135, 2018. eLIBRARY ID: 36825119

[13] T.V. Filatov, Introduction to the technology of philosophizing. Samara: Samven, 1995, 244 p.

[14] V.A. Kutyrev, Spirited Away by Progress: The eschatology of life in a technogenic world. St. Petersburg: Aletheia, 2016, 300 p.

[15] O.A. Mosina, R.A. Akhtaov, "The strategic directions of modern gerontogenesis", Modern probl. of sci. and ed., no 3, p. 18, 2019 eLIBRARY ID: 38732308 